\title{
Spatial diffusion of COVID-19: An econometric-based approach.
}

\author{
Phani Devarakonda ${ }^{1}$, Ravi Sadasivuni ${ }^{1}$, Jianhong $\mathrm{Wu}^{2}$, and David Shaw ${ }^{3}$ \\ ${ }^{1}$ Andhra University \\ ${ }^{2}$ York University Department of Mathematics and Statistics \\ ${ }^{3}$ Mississippi State University
}

May 28, 2021

\begin{abstract}
An understanding of how infected-susceptible populations interact is critical to identify underlying causal factors and disease transmission patterns of infectious diseases. Disease transmission patterns are dynamic, non-linear, and spatially complex. This anisotropic characteristic of disease spread necessitates the ideal solution to be sensitive to the geographic context. A Spatial Diffusion Model (SDM) to predict interaction potential and COVID-19 risk probability is developed by adapting the Newtonian gravity model. This novel approach overcomes the limitations of existing epidemiological studies by characterizing the behavioral patterns of the infected population to model the spatiotemporal transmission of disease across the geographic space. The proposed model is robust as it couples a multicriteria behavioral pattern to enhance predictive capability. The model shows an $83.74 \%$ correlation with the observational COVID-19 case data. The highest risk patterns for COVID-19 are predicted in the neighborhoods of New York City (NYC), exhibiting clustered socioeconomic disparities along with racial and ethnic heterogeneity. Policymakers can use these results to identify neighborhoods at high risk for becoming hot spots; efficiently match community resources with needs, and ensure that the most vulnerable have access to equipment, personnel, and medical interventions. This study emphasizes the need for improved spatial epidemiological models including enhanced depictions of human activity patterns and the need to integrate spatial data with advanced mathematical models.
\end{abstract}

\section{Hosted file}

Main_document.docx available at https://authorea.com/users/416512/articles/524032-spatialdiffusion-of-covid-19-an-econometric-based-approach

\section{Hosted file}

Table 1.docx available at https://authorea.com/users/416512/articles/524032-spatialdiffusion-of-covid-19-an-econometric-based-approach

\section{Hosted file}

Table 2.docx available at https://authorea.com/users/416512/articles/524032-spatialdiffusion-of-covid-19-an-econometric-based-approach 